\title{
MODELING, SIMULATION AND OPTIMIZATION ANALYSIS OF STEERING KNUCKLE COMPONENT FOR RACE CAR
}

\author{
Razak I.H.A ${ }^{1}$, Yusop M.Y.M², Yusop M.S.M ${ }^{3}$, Hashim M.F ${ }^{4}$ \\ ${ }^{I}$ Mechanical \& Manufacturing Section, Universiti Kuala Lumpur Malaysia France Institute, Bandar Baru Bangi, \\ Malaysia \\ ${ }^{2}$ Mechanical \& Manufacturing Section, Universiti Kuala Lumpur Malaysia France Institute, Bandar Baru Bangi, \\ Malaysia \\ ${ }^{3}$ Mechanical \& Manufacturing Section, Universiti Kuala Lumpur Malaysia France Institute, Bandar Baru Bangi, \\ Malaysia \\ ${ }^{4}$ Department of Mechanical, Institut Kemahiran Belia Negara, Dusun Tua, Malaysia
}

\begin{abstract}
Light weight and low fuel consumption are the two main demands for a vehicle, particularly for a race car. Steering knuckle, as one of the critical components of a race car, is the main subject in the present study. A light weight and optimized design of steering knuckle is proposed to be used for an EIMARace race car; a small high-performance formula-style car, with suitable material selection as well as valid finite element analysis and optimization studies. First part of this study involves modeling of steering knuckles and analysis of the stresses and displacement under actual load conditions. A CAD and FEA software; SolidWorks, is applied for modeling as well as for static analysis studies. Shape optimization is the second part of this study, utilizing solid Thinking software from Altair Engineering packages. The improved design obtained had achieved $45.8 \%$ reduction of mass while meeting the strength requirement.
\end{abstract}

Keywords: Steering knuckle, FEA, Optimization, Race car.

\section{INTRODUCTION}

Educational Innovative Motorsport and Automotive Race (EIMARace) that organized by Universiti Teknologi Malaysia (UTM) is an inter-institutional program that open to international and public higher education institutes, highlighting education through motorsports. Participating in this challenge inspires students to conceive, design, fabricate, and compete with small formula-style racing cars. The present study however will focus on development of one of the race car components; steering knuckle.

Steering knuckle is a part of vehicle suspension system which allows the steering arm to turn the front wheels and supports the vertical weight of the vehicle. Also known as spindle, upright, and hub, the steering knuckle is consists of wheel hub or spindle, and attached to the suspension components, lower and upper arm, and tie rod. It basically is assembled with front tire and spindle that rotates in a stable plane of motion by a suspension assembly. Since it is subjected to time varying loads during its service life, design of the better steering knuckle is a crucial aspect in the product development cycle.

Steering knuckle is not a standard part of vehicle component. Thus the design may differ to fit all sorts of applications and suspension types [1]. In the present study, design of a reliable and durable steering knuckle for a race car being an ultimate aim to be achieved. Development of race car components is basically tied with the regulations drawn by the organizer. Able to complete 15 laps within minimum time with only 5 liter of fuel are the prominent requirements. Therefore, the need of light weight components is vital. It is because the minimal weights will gives substantial impact to fuel efficiency [1-3], efforts to reduce emissions and therefore, might save the environment [1]. In addition, particularly the steering knuckle, according to Babu et al. [4], the lighter steering knuckle may produce greater power and less vibration, results from the less inertia. Besides need to be as light weight as possible, the component also must be very strong and rigid, due to harsh and high time varying loads for the race car driving conditions.

This paper is aimed to propose an improved design of a light-weight steering knuckle for an EIMARace car. The model developments are starting from modeling, material selection, finite element analysis (FEA) and finally optimization process.

\section{METHODOLOGY}

This study has been dealt with two parts. First part of this study involves modeling of steering knuckles and analysis of stresses and displacement under actual load conditions. CAD models of steering knuckle were developed in $3 \mathrm{D}$ modeling software, SolidWorks. The stress analysis and stiffness of the models were then obtained and compared using finite element analysis (FEA) via SolidWorks Simulation software. While the second part is shape 
optimization as weight or mass reduction purpose utilizing solidThinking software from Altair Engineering. Weight of the proposed design of steering knuckle is then being compared to the current component that been used for the previous race car in the EIMARace competition. Approach of this study is shown in Fig -1.

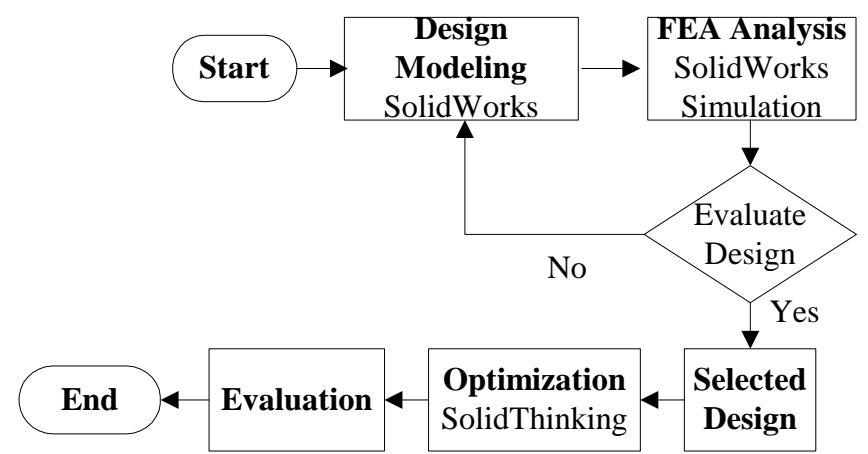

Fig -1: Flowchart for methodology

\section{MODELING AND STRESS (FEA) ANALYSIS}

In the first part of this study, five CAD models of the steering knuckle were developed and stress analysis were carried out via FEA simulation to obtain the best design which has minimum stress distribution and high stiffness as well as light weight. In addition, machinability criteria also have to take into consideration for ease of fabrication purpose.

\subsection{Design Modeling}

The design process were started with preliminary study on the current steering knuckle component used for the previous race car including investigating the existing knuckle design especially from the published design of Formula Society of Automotive Engineering (Formula $\mathrm{SAE}$ ). The design also needs to follow the criteria and regulations drawn by EIMARace organizer, which the size should be mainly depends on suspension as well as steering geometry. The previously steering knuckle was made by mild steel (yield strength $282.69 \mathrm{MPa}$ ) and the mass is about $1.9 \mathrm{~kg}$.

In general, a steering knuckle has three connections on the body part; connection to the tie rod, upper arm and lower arm. Therefore the designs need to stress on these three connections, as well as one side of connectors where brake caliper is attached. Five conceptual designs were developed in CAD software, SolidWorks, with the overall dimensions are approximately $170 \mathrm{~mm}$ X $142 \mathrm{~mm}$ X $37 \mathrm{~mm}$ thickness. The designs are illustrated in Fig -2 .

Referring to Fig. 2, the first design has its own characteristic. It has enough space to tie screw and nut, and tie rod from steering is tied separately. Yet, the disadvantage was the tie rod that tied on a flange may disturb the space of knuckle in rim diameter. To overcome this problem, the second design was generated. However, the tie rod needs to tie very near to the lower arm place which is not very suitable for a front knuckle. It will cause the tie rod shaft and lower arm to touch with each other during cornering position of the race car. Base on this situation the third design was generated.

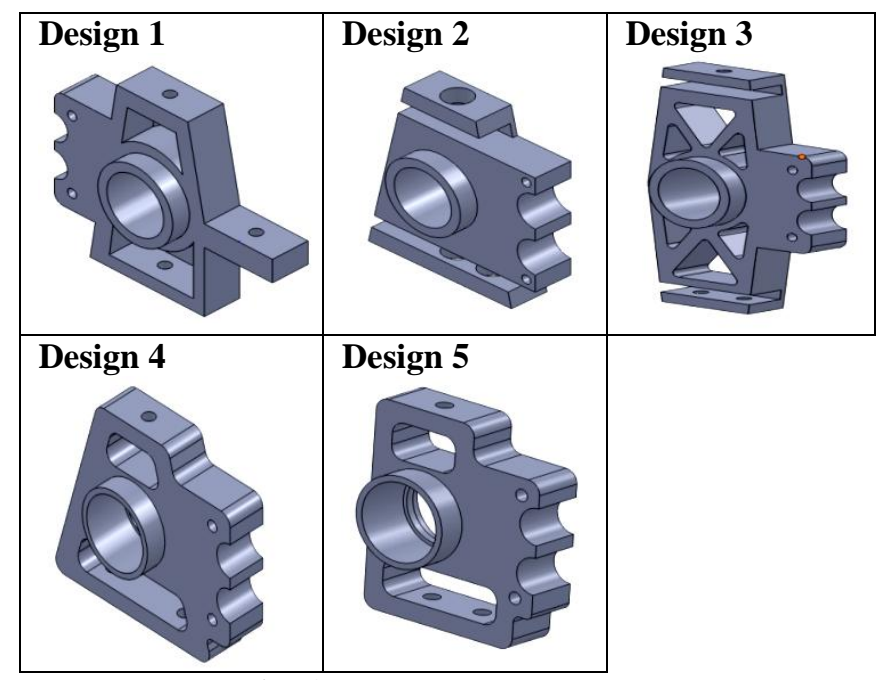

Fig -2: The conceptual design

The third design had many pockets for minimal material consumption purposes that make the knuckle light weight. However, the screw and nut will be difficult to tie and the hole of upper arm and lower arm are not aligned which will make the knuckle unstable. To overcome this problem the forth design was generated which was made in a small shape and simple. But this knuckle had drawback which the place for upper and lower arms were not in align position. When the lower hole is aligned to center line, the design may excess the left side of the knuckle. This will harm the material of product. Therefore, to improve the design, the shape on left side of this knuckle is designed in straight shape as in Design 5. The five models are then evaluated through FEA simulation in order to estimate the stress distribution, deflections as well as the weight.

\subsection{Stress Analysis (FEA)}

Finite element analysis (FEA) is a numerical computerized analysis that allows creating model geometry, applying certain loads and boundary conditions, and meshing process with aims to numerically calculate the predicted stresses and deflections of that geometry. A simple FEA package, SolidWorks Simulation was applied to run stress analysis on the five designs. Material selected and boundary conditions are brief as the following.

\subsubsection{Material Selection}

The steering knuckle in fact has complex restraint as well as constraint conditions and tolerates a combination of loads [5]. It is because the part is connected to the steering parts and strut assembly from one side and the wheel hub assembly from the other. In addition, Triantafyllidis et al. [5] claimed that parameters such as internal defects, stress concentrations and gradients, surface finish, and residual stresses can have considerable influence while designing for fatigue. 
According to DuVall and Hillis [6], three important criteria for the selection of materials are the mechanical, chemical and physical properties. In general, materials such as S.G. (ductile iron), white cast iron and grey cast iron being the preferred material to manufacture the steering knuckle [1, 3,7]. Yet, according to Sharma [3], aluminum alloy is the best alternative for nowadays automobile industry due to the light weight properties as well as has low density and compatible yield strength. In the present study, one type of aluminum alloy was selected which is Aluminum 6061T651 alloy. The T651 is referring to heat treated solution, stress-relieved stretched, then artificially ages (precipitation heat treatment) for harden the material. Table -1 depicts the physical and mechanical properties of the Aluminum 6061T651 alloy.

Table -1: Physical and mechanical properties of the Aluminum 6061-T651 alloy [8]

\begin{tabular}{|l|l|}
\hline \multicolumn{2}{|l|}{ Physical Properties } \\
\hline Density & $2.7 \mathrm{~g} / \mathrm{cc}$ \\
\hline Mechanical Properties \\
\hline Ultimate Tensile Strength & $310 \mathrm{MPa}$ \\
\hline Tensile Yield Strength & $276 \mathrm{MPa}$ \\
\hline Modulus of Elasticity & $68.9 \mathrm{GPa}$ \\
\hline Poisson's Ratio & 0.33 \\
\hline Fatigue Strength & $96.5 \mathrm{MPa}$ \\
\hline Shear Strength & $207 \mathrm{MPa}$ \\
\hline
\end{tabular}

\subsubsection{Model Boundary Conditions}

In this study, observation of maximum stress and deflections of the steering knuckle models are subjected to extreme condition. Two types of load acting on knuckle are considered; force and moment. Table 2 represents the loading conditions as suggested by Sharma et al. [3], taking consideration of the $\mathrm{G}$-force during braking action.

Table -2: Loading conditions

\begin{tabular}{|l|l|}
\hline Braking force & $1.5 \mathrm{G}$ \\
\hline Lateral force & $1.5 \mathrm{G}$ \\
\hline Steering force & Steering effort of 40-50N \\
\hline
\end{tabular}

Sharma et al. [3] applied the combination of 1.5G braking force and $1.5 \mathrm{G}$ lateral acceleration to their model of steering knuckle considering the longitudinal load transfer during braking and lateral load transfer during cornering. Thus, braking moment is applied as load on the steering knuckle side where brake caliper component is attached. Adopting this theory on the present study, the braking moment is calculated by multiplying the force acting (G-force) with perpendicular distance. In this case, the G-force, according to theory, is the weight of a car as supported at a knuckle. In the present study, an overall weight of the EIMARace single seated car is approximately $2500 \mathrm{~N}$, which a steering knuckle will get about $625 \mathrm{~N}$ loads (for a four wheels car). While, perpendicular distance is the distance from center point of bearing component to the center point of brake caliper nut, which is $101 \mathrm{~mm}$. Therefore, the braking moment is computed as $94,687.5 \mathrm{Nmm}$.

Referring to Table 2, steering force is a load acted at the steering knuckle connector where tie rod is tied from the car's steering rack. In this case, $50 \mathrm{~N}$ is applied in case of extreme condition. Apart from that, the connectors to the upper and lower arms are subjected to $312.5 \mathrm{~N}$ each; which the weight of car supported at a knuckle is divided equally to the upper and lower arms connectors. Fig -3 illustrates the loads applied and its directions on one of the steering knuckle models.

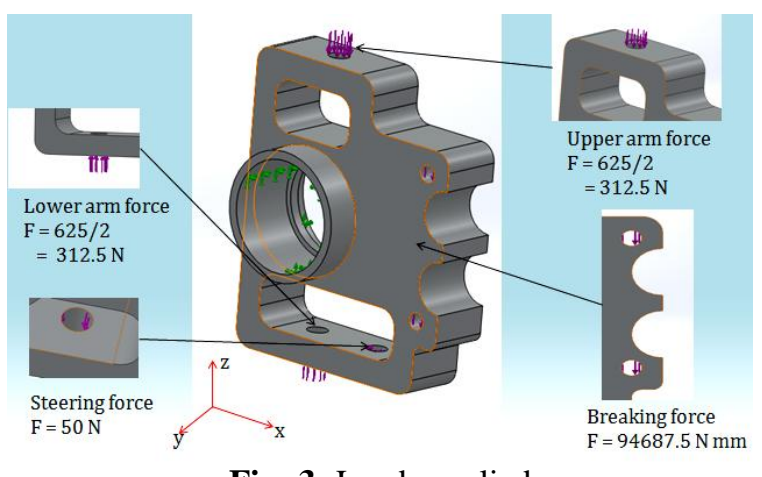

Fig -3: Loads applied

\subsubsection{FEA Analysis}

FEA analysis is carried out using one of the design analysis tool; SolidWorks Simulation. The software contains of three stages; pre-processing stage which type of analysis, material properties, loads (boundary conditions) and restraints are defined, and the model is meshed or split into finite elements; processing stage where the desired result is computed and solved; and post-processing stages where the results are interpreted.

The steering knuckle models developed in this study were analyzed using static analysis to numerically estimate the stresses and deflections on each geometry with Aluminum 6061-T651 alloy (yield strength $276 \mathrm{MPa}$ ) as material under boundary conditions as mentioned before. The models were constraint at the circumferential surface of knuckle model where the bearing part is placed, to restraint it on all direction ( $x, y, z$ translation and $x x, y y$ and $z z$ rotation). The finite element model is developed in the SolidWorks Simulation and better quality of mesh fine element size is selected. Results of the static analysis of the five steering knuckle model are shown in Table 3.

Referring to the analysis results, the maximum stress on all the five designs are far below the material yield strength and very less deflection under the assigned loads. In addition, mass of the models are also estimated in the SolidWorks software since the ultimate aim of the current project is to design a light-weight steering knuckle. It was shown that Design 1 had very least weight, followed by Design 5 and 4 . However, design model number 5 is decided to be analyzed further. Aside from can sustain more loads and had the slightest displacement, the design had the best structure among the other designs. 
Table -3: FEA results summary

\begin{tabular}{|l|l|l|l|}
\cline { 2 - 4 } \multicolumn{1}{c|}{} & $\begin{array}{l}\text { Maximum } \\
\text { Von Misses } \\
\text { Stress (MPa) }\end{array}$ & $\begin{array}{l}\text { Maximum } \\
\text { Displacement } \\
(\mathbf{m m})\end{array}$ & $\begin{array}{l}\text { Estimated } \\
\text { Mass (kg) }\end{array}$ \\
\hline Design 1 & 17.3 & 0.005 & 1.0 \\
\hline Design 2 & 19.2 & 0.089 & 1.4 \\
\hline Design 3 & 21.5 & 0.078 & 1.5 \\
\hline Design 4 & 18.7 & 0.005 & 1.3 \\
\hline Design 5 & 16.5 & 0.004 & 1.2 \\
\hline
\end{tabular}

\section{OPTIMIZATION}

Optimization is carried out by solidTinking; one of industrial design software for 3D modeling and rendering as well as known as a simulation-driven design tool. In general, the main purpose of shape optimization analysis is to obtain the best use of material for a body, involves optimizing the distribution of material thus maximizing the structure stiffness for a set of load [3]. In the current study, the aim is to reduce weight and shape of the steering knuckle model in an optimum condition without affecting durability of model designed. The chosen model; Design 5 was optimized to get the optimum shape and weight. The material, fixtures, and loads were applied same as in the FEA analysis. Figure 4 illustrates the shape optimization results obtained using solidThinking, showing that the low stress area of material that not bear the load was removed from the model. According to this result, the shape was refined in SolidWorks and the final design is shown as in Fig -4 .

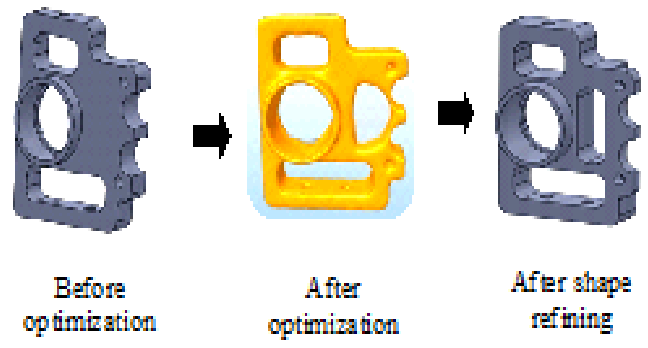

Fig -4: Optimization process for steering knuckle model

The optimized design was then re-analyzed in SolidWorks Simulation with the same loading conditions and observed for displacement and stress pattern. This is in order to ensure the final design meet the design criteria and prove by FEA method. It is observed that the maximum stress and displacement are induced in the same region as that in the earlier geometry before optimization. The contour highlights maximum stress value as $14 \mathrm{MPa}$ (yield strength is 276 $\mathrm{MPa}$ ) and maximum displacement as $0.004 \mathrm{~mm}$. This indicates that the stress pattern remains same and the values are below the save values. The optimized model also shows the reduction of mass about $14.2 \%$ as compared to the model before optimization.

Fig -5 shows the stress and displacement contour of the optimized model of the steering knuckle while the summary of results is depicted in Table 4. As compared to the mass of steering knuckle that previously used in the EIMARace competition, the improved and optimized design may achieves $45.8 \%$ reduction of mass. It was informed earlier that the previously steering knuckle used mild steel (yield strength $282.69 \mathrm{MPa}$ ) and the mass is about $1.9 \mathrm{~kg}$.

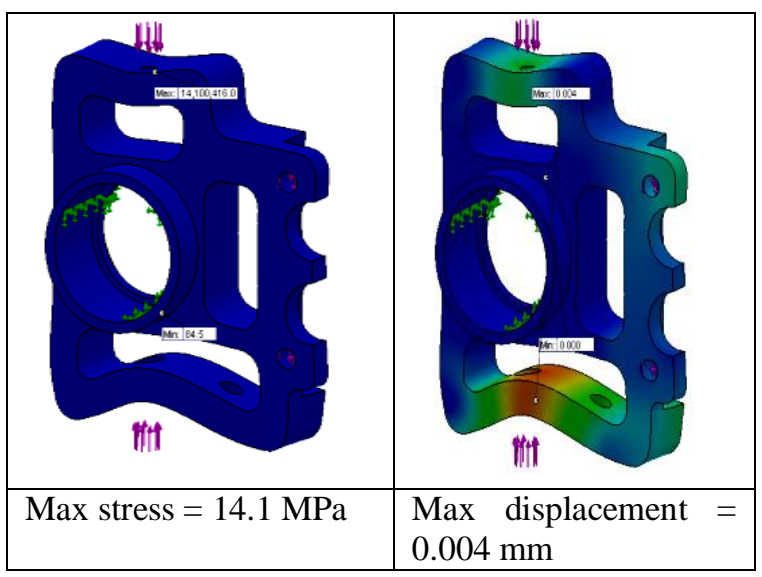

Fig -5: Analysis result

Table -4: Summary of result

\begin{tabular}{|l|l|l|l|}
\cline { 2 - 4 } \multicolumn{1}{c|}{} & $\begin{array}{l}\text { Maximum } \\
\text { Von Misses } \\
\text { Stress (MPa) }\end{array}$ & $\begin{array}{l}\text { Maximum } \\
\text { Displacement } \\
(\mathbf{m m})\end{array}$ & $\begin{array}{l}\text { Estimated } \\
\text { Mass (kg) }\end{array}$ \\
\hline $\begin{array}{l}\text { Previous } \\
\text { Design }\end{array}$ & 11.8 & 0.02 & 1.9 \\
\hline Design 5 & 16.5 & 0.004 & 1.2 \\
\hline $\begin{array}{l}\text { Optimized } \\
\text { Design }\end{array}$ & 14.1 & 0.004 & 1.03 \\
\hline $\begin{array}{l}\text { \% } \\
\text { Reduction }\end{array}$ & & & $45.8 \%$ \\
\hline
\end{tabular}

\section{CONCLUSION}

The proposed design of steering knuckle to be applied for an EIMARace car was successfully fulfills the competition requirement. As the ultimate aim of this study is to reduce mass of the existing knuckle with target to achieve low fuel consumption, selection of the best material and simple geometry are crucial. Aluminum 6061-T651 alloy (yield strength $276 \mathrm{MPa}$ ) was found to be the best material for the component due to the good physical and mechanical properties as well as light weight. It was analyzed through FEA simulation that the five models of the knuckle are below the save values and very less deflection under the assigned loads. The model design number five was selected to be analyzed further taking consideration of the good stress results, good and simple geometry as well as minimum in weight. In addition, the optimization method carried out to obtain the best use of material for the component was justified in reducing the weight of existing knuckle to $45.8 \%$ while meeting the strength requirement. The minimal weight of the steering knuckle component may contribute to the reduction of the overall weight of the race car thus may improve the fuel efficiency as well as the overall performance. 


\section{REFERENCES}

[1] Dumbre, P., Mishra, A.K., Aher, V.S., and Kulkarni, S.S. (2014). Structural analysis of steering knuckle for weight reduction, International Journal of Advanced Engineering Research Studies, April-June.

[2] Wan Muhamad, W.M., Sujatmika, E., Hamid, H. and Tarlochan, F. (2012). Design improvement of steering knuckle component using shape optimization, International Journal of Advanced Computer Science, Vol. 2, No. 2, pp. 65-69.

[3] Sharma, M.P., Mevewala, D.S., Joshi, H. and Patel, D.A. (2014). Static analysis of steering knuckle and its shape optimization, Journal of Mechanical and Civil Engineering, pp. 34-38.

[4] Babu, B., Prabhu, M., Dharmaraj, P., and Sampath, R. (2014). Stress analysis on steering knuckle of the automobile steering system, International Journal of Research in Engineering Technology, Vol. 3, No. 3, pp. 363-366.

[5] Triamtafyllidis, G.K., Antonopoulos, A., Spiliotis, A., Fedonos, S. and Repanis, D. (2009). Fracture Characteristics of Fatigue Failure of a Vehicle's Ductile Iron Steering Knuckle, Journal of Failure Analysis and Prevention, Vol. 9, No. 4, pp. 323-328.

[6] DuVall, J.B. and Hillis, D.R. (2012). Manufacturing Process, United States of America, $3^{\text {rd }}$ Edition: The Goodheart-Willcox Company, Inc.

[7] Kulkarni, V.R. and Tambe, A.G. (2013). Optimization and finite element analysis of steering knuckle, Altair Technology Conference, India, pp. 1-8.

[8] Glemco Inc. (n.d.) [Online]. Available from World Wide Web: http://www2.glemco.com/pdf/NEW_MARTERIAL_LI ST/Alumina\%206061-T6.pdf [access July 2014].

\section{BIOGRAPHIES}

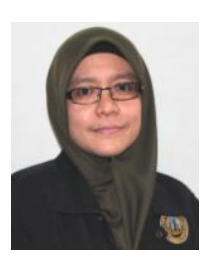

Razak, I.H.A is currently a lecturer in the Mechanical and Manufacturing Section at Universiti Kuala Lumpur Malaysia France Institute. Her research interests include manufacturing system and design.

E-mail:izatulhamimi@unikl.edu.my

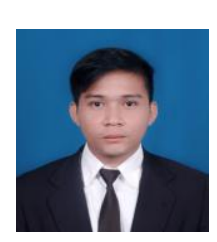

Yusop, M.Y.M graduated with a Bachelor of Engineering Technology in Machine Tools Manufacturing at Universiti Kuala Lumpur Malaysia France Institute. His research interests include product design and simulation.

E-mail: yusnizal@hotmail.com

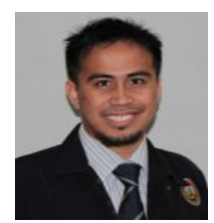

Yusop, M.S.M. is currently a lecturer in the Mechanical and Manufacturing Section at Universiti Kuala Lumpur Malaysia France Institute. His research interests include product design, mold technology and manufacturing.

E-mail: mshahrilmy@unikl.edu.my

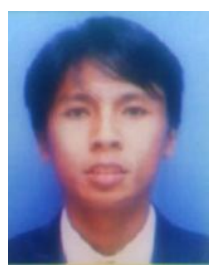

Hashim, M.F. is currently a lecturer in the Mechanical Department at Institut Kemahiran Belia Negara, Dusun Tua. His research interests include product design, automotive and manufacturing.

E-mail: faisoul@kbs.gov.my 